(c) 1968 by Academic Press Inc.

Experimental Cell Research 53,11-17 (1968)

\title{
THE EFFECTS OF CHLORAMPHENICOL ON MITOSIS OF PHYTOHEMAGGLUTININ STIMULATED HUMAN LEUKOCYTES
}

\author{
C. E. NASJLETI and H. H. SPENCER \\ Veterans Administration Hospital and The University of Michigan, \\ Ann Arbor, Mich. 48105, USA \\ Received February 20, 1968
}

Chloramphexicol (CM) was isolated two decades ago from culture filtrates of Streptomyces venezuelae, subsequently identified chemically and later synthesized. High doses of $\mathrm{CM}$ in dogs induced inanition, marrow hypocellularity, and high mortality $[20]$. Chloramphenicol has a relatively simple structure and may work as a metabolic analogue. It may act as an analogue to phenylalanine [24], and to a pyrimidine ribonucleotide [10].

Chloramphenicol exerts its antibiotic action specifically by inhibiting the synthesis of bacterial protein without directly affecting other metabolic processes $[3,23]$. Studies on the mechanism by which $\mathrm{CM}$ inhibits protein synthesis in microbial cell-free systems indicate that inhibition occurs at a stage following the attachment of amino acids to soluble RNA (sRNA) and at a site related to the ribosomal assembly of amino acids on template RNA $[6,11,16$. Chloramphenicol does not affect the activation of amino acids [6] or the transfer of amino acids to sRNA [11], but does inhibit the transfer of activated amino acids from shNA to ribosomes [16].

When CM was added to a culture of Escherichia coli B 10 min after infection with bacteriophage 'T2, the synthesis of deoxyribonucleic acid (DNA) proceeded in the absence of protein synthesis, and the nucleic acid produced had the characteristic base composition of bacteriophage DNA [4]. In this system with CM the DNA will undergo genetic damage by ultraviolet light [22], and it also can undergo genetic recombination [9]. Furthermore, mutations can be produced in the DNA of phage T2 synthesized in the presence of CM [2], and low concentrations induce abnormal shapes in bacteria [19].

However, mammalian cells in tissue culture may be as susceptible as bacterial cells to inhibition by CM $[1,7]$. Mammalian cells were inhibited when exposed to low or bacteriostatic levels of CM for extended periods of time. Chloramphenicol inhibited the antibody synthesis in cultures of rabbit 
lymph nodes after antigenic stimulation [1], and the protein synthesis in strain D98S cells derived from human bone marrow [7]. The CM in the rabbit cells may have inhibited antibody synthesis by interfering with the function of new messenger RNA formed in response to the antigenic stimulus and the inhibition of the protein synthesis observed in treated bone marrow cultures may be due to a similar mechanism [7].

Moreover, CM has shown antigenic properties when attached to bovine gamma globulin with the production of a specific antibody when injected into rabbits [8].

Because of these striking effects on macromolecular synthesis, tests of the activity of CM on human somatic cells in culture were carried out. Human cultured leukocytes stimulated with phytohemagglutinin (PHA) were treated with various concentrations of $\mathrm{CM}$ to see the effect this drug has on (1) lymphocyte blast transformation induced by PHA, (2) mitotic activity, and (3) the chromosomes of these blastoid cells.

\section{MATERIALS AND METHODS}

The observations reported in this study were obtained from leukocytes of 10 individuals, 7 normal adult females and 3 normal adult males between the ages of 20 and 40 with no history of prior drug ingestion, radiation exposure, or recent viral infection. Peripheral blood leukocytes were separated by means of erythrocyte sedimentation at room temperature for $1 \mathrm{~h}$, and were grown in culture for 3 days according to the technique described by Moorhead et al. [13]. From 10 to 15 cultures were prepared from each donor with a control culture of the same individual's leukocytes running concurrently in each case. Each standard culture consisted of 10 million cells in $10.2 \mathrm{ml}$ of medium ( $2 \mathrm{ml}$ of homologous plasma, $8 \mathrm{ml}$ of TC- 199 , and $0.2 \mathrm{ml}$ of phytohemagglutinin $\mathrm{M}$ (Difco)), and were incubated at $37^{\circ} \mathrm{C}$. Colcemide (Ciba) $0.05 \mu \mathrm{g} / \mathrm{ml}$ was added $3 \mathrm{~h}$ prior to termination of the cultures to accumulate metaphases. After 3 days of incubation the cells were harvested as previously described [15]. The chloramphenicol used was kindly provided by Parke, Davis \& Company. It was freshly prepared for each experiment, dissolved in normal saline at $27^{\circ} \mathrm{C}$, and added to separate cultures at 0,24 , and $48 \mathrm{~h}$. Control cultures were established with 700 units of penicillin $\mathrm{G}$ and $0.7 \mathrm{mg}$ of streptomycin, while in treated cultures the final concentration of CM varied from $9.69 \mu \mathrm{g} / \mathrm{ml}\left(3 \times 10^{-5} M\right)$ to $96.9 \mu \mathrm{g} / \mathrm{ml}\left(3 \times 10^{-4}\right.$ $M$. These antibiotics in solution were sterilized by filtration and incorporated in the medium to give the final concentrations noted. Chloramphenicol treated cultures were also studied with penicillin and streptomycin, but the presence of the 2 commonly used antibiotics made no difference in the results.

After resuspending the cells, an aliquot of 0.2 to $0.5 \mathrm{ml}$ was removed and Wright stained coverslips were made to examine the morphology of these cells. To estimate mitotic activity, the percentage of mitotic cells and of transformed cells were determined by counting the number per 1000 mononuclear cells. The process of lymphocyte 
transformation includes cellular enlargement, a decrease in density of chromatin clumping and the appearance of prominent nucleoli. To insure counting consistency, only those cells containing 1 or more distinct nucleoli were scored as transformed cells.

Cytogenetic studies were performed with these cells at 3 days, and some studies were performed at 4 days as well.

\section{Blast transformation}

\section{RESULTS}

Normal human lymphocytes following PHA stimulation in cultures will transform into large, pyroninophylic, nucleolated blast cells, which are capable of mitotic activity. Similar transformation has been noted with tuberculin [17], and tetanus toxoid [15]. It would appear that this phenomena may be the result of antigenic stimulation [5].

Initially, in both control and CM treated cultures the cells present consisted mainly of 2 lypes of lymphocyles. The first type were small cells with a thin cytoplasmic rim, and the second type were lymphocytes with more cytoplasm and slightly eccentric nuclei. After $24 \mathrm{~h}$ of culture, immature appearing lymphocytes and fully-developed PHA blasts appeared. The blasts were irregular, had abundant vacuolated cytoplasm and 1 or several nucleoli. At $72 \mathrm{~h}$ the cultures consisted of small lymphocytes ( 25 per cent), large mononuclear cells resembling blasts ( 75 per cent), and an occasional granulocyte. The percentage of blastoid cells in all CM treated cultures was the same as in the controls, indicating that CM had no effect on blast transformation.

Mitotic index

The inhibitory effect on leukocyte mitoses by $\mathrm{CM}$ in concentrations varying from 9.69 to $96.9 \mu \mathrm{g} / \mathrm{ml}$ is demonstrated in Fig. 1. Twelve thousand cells

Fig. 1.-Effect of chloramphenicol in mitotic rates of leukocytes derived from 6 sensitive donors. Abscissa: Hours of treatment; ordinate: mitotic rates (\%).

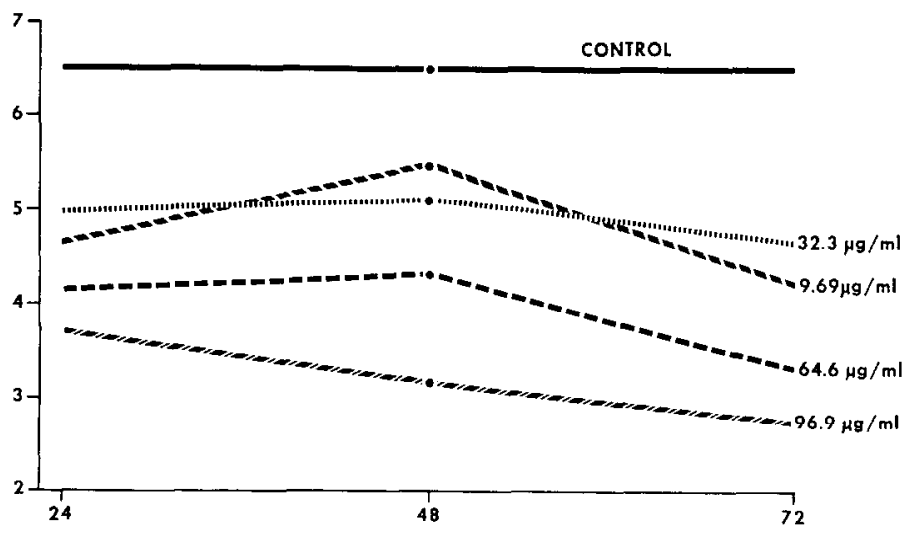

Experimental Cell Research $\mathbf{5 3}$ 


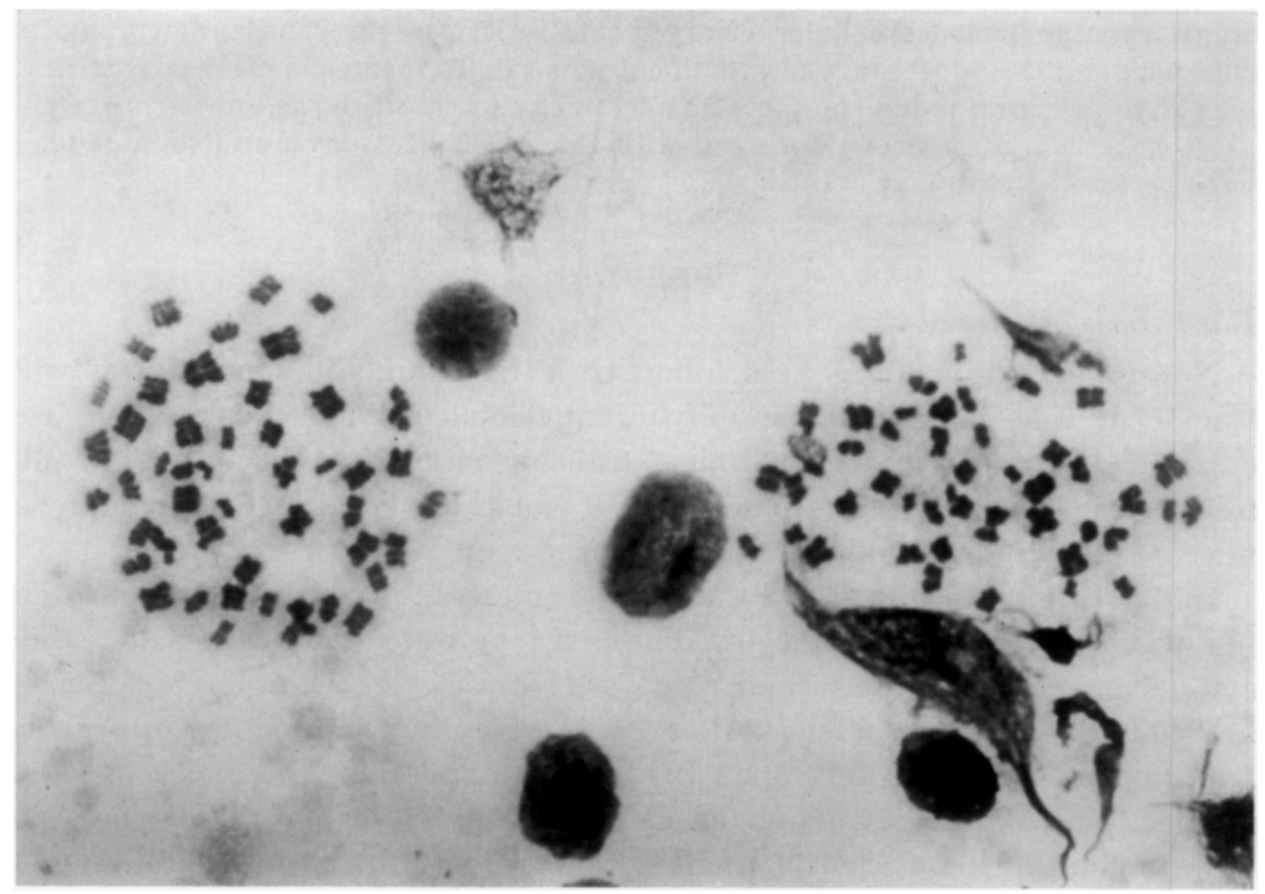

Fig. 2.-Chloramphenicol induced endoreduplicated tetraploid metaphases in 4-day cultures of human leukocytes. $\times 640$.

were scored on the control slides, and approx. 4000 cells were counted for each treatment. The mitotic index for the controls at $72 \mathrm{~h}$ was 6.5 per cent. Four individuals did not show depression of the mitotic index at any time. The data obtained from 6 CM sensitive donors are presented in Fig. 1. Since no significant differences were demonstrated among the 6 subjects or between sexes, the data from all subjects are pooled for each treatment.

There was a rough linear relationship between the amount of CM present and the decrease in mitotic activity. Concentrations of 9.69 and $32.3 \mu \mathrm{g} / \mathrm{ml}$ of CM showed no significant mitotic inhibition in these cultures. However, doses of 64.6 and $96.9 \mu \mathrm{g} / \mathrm{ml}$ demonstrated inhibition. In the $72 \mathrm{~h}$ cultures the greatest inhibition of mitosis occurred with the higher concentrations, when $\mathrm{CM}$ was added at zero time. Much less inhibition was noted when the drug was added to the cultures at 24 and $48 \mathrm{~h}$.

\section{Cytogenetic studies}

Chromosome preparations were made with control and CM treated cells at 3 and 4 days of cultivation. In the 3 day cultures, both controls and treated 
cells were normal from all 10 individuals. Chromosomes were normal not only in their morphology but also in number.

In 4 day cultures, the structural configuration of chromosomes was normal in all cultures. The chromosomal number was also normal in the 4 donors who did not show mitotic inhibition in the CM treated cultures. However, in

TABLE 1. Incidence of polyploidy in six donors

Four day cultures

\begin{tabular}{crrcc}
\hline $\begin{array}{c}\text { CM dosage } \\
(\mu \mathrm{g} / \mathrm{ml})\end{array}$ & $\mathrm{T}$ & TE & $\begin{array}{c}\text { Total } \\
\text { mitosis }\end{array}$ & $\begin{array}{c}\text { Polyploidy } \\
(\%)\end{array}$ \\
\hline 9.69 & 6 & 0 & 600 & 1.0 \\
32.3 & 9 & 3 & 600 & 2.0 \\
64.6 & 9 & 9 & 600 & $3.0^{a}$ \\
96.9 & 15 & 27 & 600 & $7.0^{a}$ \\
\hline
\end{tabular}

Incidence of tetraploid mitoses $(\mathrm{T})$ with random chromosome distribution and endoreduplicated tetraploid mitoses (TE) in human leukocyte cultures treated with chloramphenicol (CM).

${ }^{a}$ Includes one octoploid endoreduplication.

the 6 donors who showed mitotic inhibition with $C M$, an increased percentage of cells containing multiples of the diploid chromosomal number were observed. Almost all the polyploid mitosis observed were tetraploid, but there were occasional octoploid mitoses, Fig. 2. These tetraploid cells showed diplochromosomes characteristic of endoreduplication, as well as randomly distributed chromosomes.

\section{DISCUSSION}

In these experiments, the higher concentrations of CM did not interfere with the normal blast transformation of lymphocytes stimulated with PHA. Similar findings have been recently published $[18\rceil$.

Definite inhibition of the mitotic index was noted in 6 of the 10 individuals tested when CM was added to the cultures. The explanation for this mitotic inhibition is not known but CM may act on spindle formation. Chloramphenicol does inhibit bacterial protein synthesis [23], and in dividing cells at least 95 per cent of the spindle is protein in nature [12]. Further, when CM was added to newt cells in culture, it prevented the formation of a mitotic spindle of sufficient size to function efficiently. These newt cells continued to synthesize DNA, although they did not divide $[21]$. It is also possible that the synthesis of individual enzymes or other specific proteins necessary for spindle formation might be inhibited. Others have found that CM will inhibit alkaline 
phosphatase, amylase, aldolase, succinic dehydrogenase, catalase, and others [3]. Chloramphenicol did not inhibit the activity of the enzyme but only its synthesis, and higher concentrations of the antibiotic were necessary to show this effect.

In 4 day cultures, chromosomal polyploidy was observed in all individuals with a diminished mitotic index after treatment with CM. In the 4 individuals who did not show mitotic inhibition in their CM treated cultures, no polyploidy was found in the 4 day cultures. The production of tetraploidy and endoreduplication may be due to abnormalities in the spindle or to some damage to the dividing mechanism of the cell [14]. None of the 3 day cultures showed polyploidy, so a cell must have time for a second mitosis before polyploidy can be produced. These observations suggest a direct relationship between the depression of mitoses, and the induction of polyploidy by CM in these individuals. It is possible that these 2 events were induced simultaneously, but it is also possible that CM may act in different areas or at different times to produce the changes. These 2 events (suppression of mitoses and induction of chromosome polyploidy), show another effect of CM on mammalian cells, in addition to the inhibition of antibody production [1], and protein synthesis [7].

It was noted that the action of CM in our system differs markedly from that previously observed when testing the antibiotic, Streptonigrin (SN). The chicf differenec is in the ability of SN to induce chromosome morphological changes in addition to chromosomal polyploidy [14]. Streptonigrin may interfere with synthesis of nucleic acids. Chloramphenicol does not seem to directly affect nucleic acids as synthesized in human cultured leukocytes, and therefore it would seem unlikely that chromosomal structural changes could be achieved with this antibiotic in vitro.

Another observation was made concerning our group of donors. The tuberculin skin test was negative in those individuals who did not show polyploidy of chromosomes or a reduction in their mitotic index with the CM treated cultures. The 6 individuals who did show polyploidy and a decrease in their mitolic rate, had positive tuberculin skin lests. Although a small sample, this correlation suggests that there may be a difference in the immunological competence of certain donor lymphocytes, and this difference may explain to some extent the variable results found in cultures treated with CM.

\section{SUMMARY}

Lymphocyte transformation to blast cells induced by phytohemagglutinin was not inhibited by chloramphenicol in cultures. 
Chloramphenicol induced a decrease in the mitotic index in 6 out of 10 normal subjects, and these 6 individuals showed increased polyploidy in 4 day cultures. These 6 individuals were all positive to the tuberculin skin test.

In 4 out of 10 individuals the chloramphenicol treated cultures showed no diminution of mitotic index, and no evidence of polyploidy in 4 day cultures. These 4 individuals were negative to the tuberculin skin test.

We wish to acknowledge with thanks the technical assistance of Mrs Jean Simons, Mrs Virginia Hartog, Mrs Nella Nelly, and Mr Richard Shaw. Also, Mr Robert McKnight and Stanley Nance for assistance with the illustrations, and Mrs Doris Watkins for aid with the manuscripts.

\section{REFERENCES}

1. Ambrose, C. T. and Coons, A. H., J. Exptl Med 117. 1075 (1963).

2. Brenner, S. and Smith, J. D., Virology 8, 124 (1959).

3. Ввоск, T. D., Bact. Rev. 25, 32 (1961).

4. Burton, K., Biochem. J. 61, 473 (1955).

5. Cowling, D. C. and Quaglino, E., J. Pathol Bacteriol. 89, 63 (1965).

6. Demoss, J. A. and Novell, G. D., Biochim. Biophys. Acta 22, 49 (1956).

7. Djordjeyic, B. and Szybalski, W., J. Exptl Med. 112, 509 (1960).

8. Hamburger, R. N., Science 152, 203 (1966).

9. Hershey, A. D., Burgi, E. and Streisinger, B., Virology 6, 287 (1958).

10. Jardetsky, O., J. Biol. Chem. 238, 2498 (1963).

11. Lacks, S. and Gross, F., J. Mol. Biol. 1, 301 (1960).

12. Mazia, D., Symp. Soc. Exptl Biol. 9, 335 (1955).

13. Monrhean, P. S., Nowet.t, P. D., Metrman, W. J., Battips, D. M. and Hungerford, D. A., Exptl Cell Res. 20, 613 (1960).

14. Nasjleti, C. E. and Spencer, H. H., Cancer 20, 31 (1967).

15. Nasjleti, C. E., Walden, J. M. and Spencer, H. H., J. Nucl. Med. 7, 159 (1966).

16. Nathans, D. and Lipman, F., Proc. Natl Acad. Sci. US 47, 497 (1961).

17. Permain, G., Lycette, R. R. and Fitzgerald, P. H., Lancet 1, 637 (1963).

18. Pisciotta, A. V. and DePrey, C., Blood 30, 457 (1967).

19. Pulvertaft, R. J. V., J. Pathol Bacteriol. 64, 75 (1952).

20. Reuter, 'I. F., Maxwell, R. E., Weston, K. E. and Weston, J. K., Antibiot. Chemotherapy $5,679(1955)$.

21. TaYlor, E. W., J. Biophys, Biochem. Cytol. 6, 193 (1959).

22. Tomizawa, J., Virology 6, 55 (1958).

23. Weisberger, A. S. and Wolfe, S., Federation Proc. 23(5), 976 (1964).

24. WoOlley, D. W., J. Biol Chem. 185, 293 (1950). 